\title{
Article 19 of the CRC and the Criminal Justice System's Duty to Protect Children against Violence
}

\author{
Yvon Dandurand \\ School of Criminology and Criminal Justice, University of the Fraser Valley \& \\ International Centre for Criminal Law Reform and Criminal Justice Policy
}

\begin{abstract}
As it celebrates the $25^{\text {th }}$ anniversary of the adoption of the Convention on the Rights of the Child, the United Nations General Assembly adopts a new instrument to help prevent violence against children: the United Nations Model Strategies and Practical Measures on the Elimination of Violence against Children in the Field of Crime Prevention and Criminal Justice. The new instrument should help States give full effect to Article 19 of the Convention. It is the first international instrument to articulate the responsibility of the criminal justice system, in cooperation with child protection and other agencies, to prevent and respond to violence against children. The instrument aims to improve the effectiveness of the criminal justice system in preventing, prohibiting and responding to all forms of violence against children, as well as preventing any violence against children which may occur during their contacts with that system. The article introduces the new instrument, describes its main features and relates them to some of the many difficult challenges every society faces in preventing violence against children.
\end{abstract}

Keywords: violence; children; human rights; criminal justice 


\section{Introduction}

As we are celebrating the $25^{\text {th }}$ Anniversary of the Convention on the Rights of the Child (CRC), the United Nations General Assembly adopts a new practical instrument to assist States in giving full effect to the provisions of article 19 of the Convention. Its focus is on the field of crime prevention and criminal justice. The new United Nations Model Strategies and Practical Measures on the Elimination of Violence against Children in the Field of Crime Prevention and Criminal Justice (thereafter the Model Strategies) are designed to help Member States to integrate crime prevention and child protection strategies. They respond to the need to offer children the protection to which they have an unqualified right: protection against all forms of violence and, in particular, protection for vulnerable or marginalized children who find themselves in conflict with the law.

States have the duty to take appropriate measures to effectively protect children from all forms of violence. Article 19 of the Convention requires States Parties to "take all appropriate legislative, administrative, social and educational measures to protect the child from all forms of physical or mental violence, injury or abuse, neglect or negligent treatment, maltreatment or exploitation, including sexual abuse, while in the care of parent(s), legal guardian(s) or any other person who has the care of the child".

The obligations of States with respect to the protection of children and their rights are well established. The United Nations Committee on the Rights of the Child, in its General comment No. 13 (2011) - The Right of the Child to Freedom from all Forms of Violence, referred to institutional and system violations of child rights and explained that:

Authorities at all levels of the State are responsible for the protection of children from all forms of violence may directly and indirectly cause harm by lacking effective means of implementation of obligations under the Convention. Such omissions include the failure to adopt or revise legislation and other provisions, inadequate implementation of laws and other regulations and insufficient provision of material, technical and human resources and capacities to identify, prevent and react to violence against children. It is also an omission 
when measures and programmes are not equipped with sufficient means to assess, monitor and evaluate progress or shortcomings of the activities to end violence against children (para 32).

The Model Strategies are important because they are the first international instrument to fully articulate the responsibility of the police and other criminal justice institutions and agencies to prevent and respond to violence against children. They also emphasize the importance of adopting a comprehensive approach to that task. Comprehensive national planning to prevent violence against children is still the exception rather than the rule. Findings from the recent Global Survey on Violence against Children suggest some progress on national strategies or agendas to prevent and address violence against children. However, according to the replies received, only 16 per cent of countries were found to have a fully functioning comprehensive agenda to prevent and respond to all forms of violence. Several governments acknowledged that existing policy frameworks are fragmented, and 22 percent of governments indicated that no form of comprehensive agenda on violence against children is in place (SRSG-VAC, 2013, 86).

This article introduces the new instrument, describes some of its main features and relates them to many of the difficult challenges a society faces in preventing violence against children. The 47 groups of measures included in the Model Strategies can neither be presented nor discussed here in great detail. This is not the purpose here and neither is it the purpose to critique the Model Strategies or comment on their potential impact on practices within and outside the field of criminal justice and crime prevention. This must be left to a later time.

\section{Background}

In 2006, the United Nations Study on Violence against Children revealed the high incidence of various types of violence against children within the family, schools, alternative care institutions and detention facilities, places where children work and communities (United Nations, 2006). The study highlighted the particularly high risk of violence faced by various vulnerable groups of children, including children alleged as, accused of or recognised as having 
infringed the penal law, and it encouraged a discussion on the ways in which criminal justice institutions could play a more effective role in preventing and responding to such violence.

Pursuant to Human Rights Council resolution 18/12 of 24 September 2011, an expert consultation on the prevention of and responses to violence against children within the juvenile justice system took place in Vienna on 23-24 January 2012. The results of the Expert Consultation informed the "Joint report of the Office of the High Commissioner for Human Rights, the United Nations Office on Drugs and Crime and the Special Representative of the Secretary-General on Violence against Children on prevention of and response to violence against children within the juvenile justice system" (OHCHR/UNODC/SRSG-VAC, 2012). That report, submitted to the Human Rights Council in September 2012, identified the risks of violence to which children are exposed in that system and analyzed the systemic factors that contribute to such violence. This was the first exercise of this kind and appears to be something that is still rarely done at the national level.

A High Level Panel discussion on violence against children within the juvenile justice system took place at the General Assembly in its 67th Session on 8 October 2012. The main purpose of that event was to raise awareness of the issue and launch the above-mentioned report on violence against children within the juvenile justice system. As a result of that process, in November 2012, the General Assembly adopted a Resolution on "Human Rights in the Administration of Justice" which contained an invitation to the "Commission on Crime Prevention and Criminal Justice to consider developing a set of model strategies and practical measures on the elimination of violence against children in the field of crime prevention and criminal justice in consultation with all Member States and in close collaboration with all relevant United Nations entities". The Model Strategies were drafted and reviewed at an expert group meeting in Vienna in October 2013. They were discussed and negotiated at an open-ended intergovernmental expert group meeting hosted by Thailand, in Bangkok, in February 2014. In May of this year, the Model Strategies were adopted by the UN Commission on Crime Prevention and Criminal Justice and recommended for final adoption by the General Assembly. 
The Model Strategies, like the CRC, use a broad definition of violence which includes all forms of physical or mental violence, injury or abuse, neglect or negligent treatment, maltreatment or exploitation, including sexual abuse. This multidimensional nature of violence against children calls for a multifaceted response and necessitates various strategies to respond to the diverse manifestations of violence and the various settings in which it occurs, both in private and in public life, whether committed in the home, the workplace, educational and training institutions, the community or society, in the criminal justice system or in situations of armed conflict or natural disaster. The recent statistical analysis of violence against children conducted by UNICEF reveals once more how prevalent violence against children continues to be in all of these various settings (UNICEF, 2014).

As was reported to the Human Rights Council (2014) earlier this year, progress has been too slow and too fragmented to make a genuine breakthrough in the protection of children from violence:

Countless girls and boys of all ages continue to be exposed to the cumulative impact of different forms of violence as a result of reactive, ill-coordinated and ill-resourced national strategies; dispersed and poorly enforced legislation; and low levels of investment in family support and gender- and child-sensitive approaches and mechanisms to support child victims and fight impunity. Overall, data and research remain scarce and incipient insufficient to overcome the invisibility and acceptance of this phenomenon and to safeguard children's freedom from violence at all times (p. 6).

\section{The Role of the Criminal Justice System}

Article 19 of the Convention refers to the kind of protective measures that should be taken, as appropriate, to protect children against violence. These are described as: assistance and support for the child and for those who have the care of the child, as well as other forms of prevention and measures to report, identify, investigate and respond to child maltreatment. Article 19 also refers briefly to the need for effective measures "as appropriate, for judicial 
involvement" but it otherwise fails to acknowledge the role of the criminal justice system in preventing and responding to violence against children. One may argue that, at the time the CRC was adopted, there still prevailed a deep-rooted skepticism about the willingness, capacity and ability of the police and other criminal justice institutions to intervene competently, sensitively and effectively in the often delicate situations involving violence against children. Since a lot of the violence occurred in private settings, such as the family, there was great ambivalence about involving these institutions. The same was true then of the popular perception of the criminal justice system's role in responding more generally to domestic violence. ${ }^{2}$

Things may have changed since then and there may now be a greater recognition of the specific role of the criminal law and the criminal justice system within the overall institutional responses to violence against children. In spite of that progress, however, resistance to State interventions to prevent violence against children, particularly in the family context, persists in many parts of the world. For example, a report of the League of Arab States (2010) notes that a persistent challenge is that the legislative environment in the Arab world is not ready yet to put in place a legal framework that comprehensively protects children against all forms of violence, bad treatment and exploitation. It adds that: "the sensitivity of this topic, and given that it can be considered a violation of a family's privacy and interference in its affairs in some communities, poses another challenge related to this issue" (p. 182). That kind of resistance, of course, is far from being limited to the Arab world.

It is also useful to note that, since the adoption of the CRC, other international conventions and protocols were also adopted that called for the criminalization of various forms of violence against children and concurrently created an obligation for law enforcement and criminal justice institutions to prevent, investigate, punish and otherwise control these crimes. This was the case for example of the Optional Protocol to the Convention on the Rights of the Child on the sale of children, child prostitution and child pornography ${ }^{3}$ and the Protocol to Prevent, Suppress and Punish Trafficking in Persons, Especially Women and Children ${ }^{4}$. By doing so, these conventions placed a new and very clear onus on the criminal law and criminal 
justice institutions to prevent, respond, and help eliminate some of the most vicious forms of violence against children.

Nonetheless the complementary roles of the justice system on the one hand, and the child protection, social welfare, health and education sectors on the other, in creating a protective environment and in preventing and responding to violence against children is not consistently acknowledged in human rights and other international instruments and even less so in practice. The adoption of the Model Strategies should help change this situation.

\section{The Model Strategies}

The Model Strategies aim to improve the overall effectiveness of the criminal justice system in preventing, prohibiting and responding to all forms of violence against children, as well as preventing any violence against children in contact with the justice system itself. Their main purpose is to offer a comprehensive and practical framework to assist governments in the review of national laws, procedures and practices to ensure that they effectively prevent and respond to violence against children and fully respect the rights of child victims of violence in accordance with the $\mathrm{CRC}$ and other relevant human rights standards.

The Model Strategies identify measures which can prevent any further victimization of children, including the secondary victimization of children in contact with the criminal justice system, as accused, offenders, victims or witnesses. With respect to the protection of children in conflict with the law, the Model Strategies are meant to guide the review of laws, policies and procedures, as necessary, to ensure compliance with international standards and ensure that the process of juvenile justice and criminal justice reform is framed by a child- and gender-sensitive approach, promoting a juvenile justice system that is fair, effective, efficient, and established as a core dimension of the national child protection system. With respect to perpetrators of violence against children, the Model Strategies can help ensure that decisions on the apprehension or arrest, detention and terms of any form of release of an alleged perpetrator of violence against a child take into account the need for the safety of the child and people related to that child. 
The Model Strategies take into account the high risk faced by children in conflict with the law, or in the language of the CRC "children who are alleged as, accused of or recognized as having infringed the criminal law", especially those who are deprived of their liberty. Because special attention must be paid to the especially vulnerable situation of these children, the Model Strategies aim not only to improve the effectiveness of the criminal justice system in preventing and responding to violence against children, but also to protect children against any violence that may result from their contacts with that system.

Many countries have adopted laws that define and condemn various forms violence against children as serious crimes, but not all of them have insured that the police and other criminal justice institutions actually take these crimes seriously and accept their respective responsibilities with respect to child protection. Reducing violent crimes against children is not necessarily always identified as a crime prevention or policing priority. Criminal justice institutions need to strengthen and focus their efforts to prevent and respond to violence against children and to increase their diligence in investigating, convicting and rehabilitating perpetrators of violent crimes against children, so as to effectively protect children against violence.

\section{Scope and structure of the instrument}

As stated in the instrument itself, the Model Strategies were formulated in order to help States address the need for integrated violence prevention and child protection strategies and offer children the protection to which they have an unqualified right. The Model Strategies affirm the complementary roles of the justice system on the one hand, and the child protection, social welfare, health and education sectors, on the other, in creating a protective environment and in preventing and responding to violence against children.

It is a complex tool that reflects the complexity of the problem of violence against children and the need for a comprehensive approach to address this pervasive problem. Each of the strategies recommended in that instrument addresses a practical aspect of child protection against violence and offers numerous practical measures that purportedly reflect best crime prevention and child protection practices. 
The tool proposes a total of 17 strategies organized into three distinct groups: general prevention strategies to address violence against children as part of broader child protection and crime prevention initiatives; strategies to improve the ability of the criminal justice system to respond to crimes of violence against children and to protect child victims effectively; and, strategies to prevent and respond to violence against children in contact with the justice system.

Each strategy is buttressed by a varying number of related "practical measures" that are named and listed rather than fully described or explained. Some of these measures are unfortunately formulated in fairly general terms and may not always be self-evident for practitioners wishing to implement them. This is perhaps the best that could be expected from a politically negotiated text, particularly when the measures in question are expected to apply differently in different cultural, legal and institutional contexts. For the full implementation of the strategies, legislators, policy makers and practitioners will have to rely on other tools, manuals or training instruments.

Unfortunately, conclusive evidence on the effectiveness of these measures is not always available. Many of them have not been evaluated to assess their effectiveness in preventing violence against children. The frequent lack of evidence in this whole area makes it difficult to decide which measures to prioritize and which programmes to scale up, and on what justifiable basis (Proudlock, P., Mathews, A. and L. Jamieson, 2014, 180).

\section{Guiding principles}

The instrument explicitly states a number of principles to guide the implementation of the proposed strategies in accordance with international human rights law. These rights-based principles are as follows:

(a) That the inherent rights of the child to life, survival and development should be protected; 
(b) That the right of the child to have his or her best interests as a primary consideration in all matters involving or affecting him or her should be respected, whether the child is a victim or a perpetrator of violence, as well as in all measures of prevention and protection;

(c) That every child should be protected from all forms of violence without discrimination of any kind, irrespective of the child's or his or her parent's or legal guardian's race, colour, sex, language, religion, political or other opinion, national, ethnic or social origin, property, disability, birth or other status;

(d) That the child should be informed of his or her rights in an age-appropriate manner and that the right of the child to be consulted and to express his or her views freely in all matters affecting him or her, should be fully respected;

(e) That all strategies and measures to prevent and respond to violence against children should be designed and implemented from a gender perspective specifically addressing genderbased violence;

(f) That the specific vulnerabilities of children and the situations they find themselves in, including children in need of special protection and children committing criminal offences under the age of criminal responsibility, should be addressed as part of comprehensive violence prevention strategies and identified as a priority for action;

(g) That measures to protect child victims of violence should be non-coercive and strictly avoid compromising the rights of these children. Abusive protection measures must obviously be avoided. They cannot be justified as they amount to a form of violence against children.

\section{Prohibition of Violence against Children and General Prevention}

A first group of strategies emphasizes the need to prohibit by law all forms of violence against children and to specifically criminalize many serious forms of violence. It also relates to the role of criminal justice agencies, working together with child protection, social welfare, health and education agencies and civil society organizations to develop effective violence 
prevention programmes. It identifies the need for both broad and context-specific measures to prevent violence against children and challenge the ways in which such violence are tolerated. It includes research and evaluation strategies to improve the effectiveness of violence prevention and victim protection measures.

\section{Ensuring the prohibition by law of all forms of violence against children}

The first strategy (Strategy I) calls for the prohibition of all forms of violence against children. That is obvious because of the need for a sound and explicit legal framework that prohibits violence against children and mandates and empowers authorities to respond appropriately to incidents of violence. The strategy involves ensuring the prohibition of cruel, inhumane or degrading treatment or punishment of children in all settings, something which is already an obligation for State parties to the CRC. ${ }^{5}$ However, the strategy does not necessarily involve the criminalization of all forms of violence, acknowledging thereby that some forms of violence should not necessarily be defined as crime. At the same time, the strategy involves the revision of all laws (including criminal procedure law) to remove all provisions that justify, allow for or condone violence against children or may increase the risk of violence against children.

The same strategy also involves establishing by law a clear and comprehensive prohibition of all harmful practices against children, supported by detailed provisions in relevant legislation to secure the effective protection of girls and boys from those practices, to provide means of redress and to fight impunity. This is based in part on the recommendations contained in a 2012 report of the Special Representative of the Secretary General on Violence against Children on protecting children from harmful practices in plural legal systems". That report referred explicitly to the importance of safeguarding the supremacy of human rights standards and the need for States to ensure that “domestic legislation relevant to children's protection from violence and harmful practices, foreseen in statute, customary or religious laws, is in full conformity with human rights standards" (SRSG on Violence Against Children \& Plan International, 2012, p. 40). The same report also recommended legislation to ensure the 
investigation of incidents and establish the accountability of perpetrators of harmful practices against children, including those advising, attempting to, aiding or condoning those practices. It also specifies that "(a)ny agreement or payment to exempt the perpetrator from criminal or civil proceedings or sanctions should be prohibited by law" (SRSG on Violence Against Children \& Plan, 2012, p. 40). ${ }^{6}$

Taking child marriages and forced marriages as examples of sources of violence against girls, it is clear that among other driving factors such as poverty, for example, they are associated with cultural values and traditions (Gangoli, Razak, McCarry, 2006; United Nations Population Fund, 2012). Bokhari's research in the U.K. that British born children have been trafficked out of the U.K. to be forcibly married abroad, and migrant children have arrived in the U.K. (sometimes smuggled on forged identity documents making them appear older) having been forced in their country of birth into a marriage with a British citizen (Bokhari, 2009). However, whenever one refers to cultural values and practices, one may expect some defensive posturing on the part of various communities. Individuals and organizations may understandably fear ostracism and other repercussions when speaking out against such practices. “(...) even though forced marriage has been integrated into domestic violence and child abuse policy, professionals may continue to view it as a cultural and private family matter and fail to take appropriate action when cases do present" (Bokhary \& Kelly, 2010, p. 153). The truth is that these cultural values and practices, among other factors, must be challenged and prohibited as they have been successfully in many parts of the world (Phillips, 2012; United Nations Population Fund, 2012). Practitioners face some serious challenges trying to prevent some marriages from taking place and ensuring the safety and well-being of women who are already in such marriages. The U.K. government and others have adopted legal measures to prohibit such practices.

Another example is that of improper disciplinary practices in the home and the use of corporal punishment at home and in schools. The use of violent discipline in the home is widespread and has been described as the most common form of violence against children (UNICEF, 2014, 96). The Multiple Indicator Cluster Surveys (MICS) sponsored by UNICEF includes questions on child discipline. The most recent survey revealed that violent discipline is 
widespread in most of the 42 countries surveyed. In six of the seven countries surveyed in the East-Asia Pacific region, more than two thirds of children had experienced violent discipline in the home (UNICEF, 2014; Kilbanem, 2013). ${ }^{7}$

This particular strategy will be controversial in many parts of the world because it essentially affirms the supremacy of international human rights law over cultural, traditional and sometimes religious practices. It involves the removal from national legislation of any legal provisions that justify or allow for consent to harmful practices against children. It also involves ensuring that resorting to informal justice systems does not jeopardize children's rights or preclude child victims from accessing the formal justice system. As is regularly confirmed by research, countless number of girls and boys fall victim to harmful practices undertaken under different pretexts or grounds, including female genital mutilation or cutting, forced marriage, breast ironing and witchcraft rituals.

Some of these harmful practices are justified and supported by traditional justice systems. As the report of the SRSG on Violence Against Children noted: "While traditional, customary and religious adjudication mechanisms may be accessible to people at the grassroots level and play an important role in the protection of children from harmful practices, it is crucial to ensure that resorting to these mechanisms does not jeopardize children's rights or preclude child victims from accessing the formal justice system" (SRSG on Violence Against Children \& Plan, 2012, p. 40).

Prohibiting all forms of violence against children by law is a strategy that also explicitly calls also for the criminalization of various forms of violence against children, including: engaging in sexual activities with a child using coercion, force or threats, abusing a position of trust, authority or influence over a child, including within the family, and abusing a particularly vulnerable situation of a child, because of a mental or physical disability or a situation of dependence; committing sexual violence against a child, including sexual abuse, sexual exploitation and sexual harassment through or facilitated by the use of new information technologies, including the Internet; the sale of or trafficking in children for any purpose and in any form; offering, delivering or accepting, by whatever means, a child for the purpose of sexual 
exploitation of the child, transfer of organs of the child for profit or engagement of the child in forced labour; offering, obtaining, procuring or providing a child for child prostitution; producing, distributing, disseminating, importing, exporting, offering, selling or possessing child pornography; slavery or practices similar to slavery, debt bondage and serfdom and forced labour, including forced or compulsory recruitment of children for use in armed conflict; and, committing gender-related violence against a child and, in particular, gender-related killing of girls.

In some instances, the criminalization of the conduct is already required by the $\mathrm{CRC}$ or by another convention or protocol to which a State may be a party. For example, article 35 of the CRC states that: "States Parties shall take all appropriate national, bilateral and multilateral measures to prevent the abduction of, the sale of or traffic in children for any purpose or in any form", and similar criminalization requirements are found in article 1 of the Optional Protocol to the Convention on the Rights of the Child on the sale of children, child prostitution and child pornography ${ }^{8}$, the Protocol to Prevent, Suppress and Punish Trafficking in Persons, Especially Women and Children, supplementing the United Nations Convention against Transnational Organized Crime ${ }^{9}$, article 18 of the Council of Europe 2007 Convention on the Protection of Children against Sexual Exploitation and Sexual Abuse ${ }^{10}$, or article 3 of the Convention Concerning the Prohibition and Immediate Action for the Elimination of the Worst Forms of Child Labour ${ }^{11}$.

\section{Implementing comprehensive prevention programmes}

Strategy II consists of developing and implementing comprehensive prevention programmes. States are called upon to play a leadership role in developing effective crime prevention strategies and in creating and maintaining institutional frameworks for their implementation and review. ${ }^{12}$ The new instrument suggests that measures be undertaken to systematically identify and assess the specific vulnerabilities and risks faced by children in different situations or even in different part of a country. This is prerequisite to the design of proactive measures to reduce those risks and take appropriate actions to support and protect all 
children and, in particular, children in different situations of vulnerability and children in need of special protection. On the subject of prevention, the Committee on the Rights of the Child (2011) explained that:

Prevention includes public health and other measures to positively promote respectful child-rearing, free from violence, for all children, and to target the root causes of violence at the levels of the child, family, perpetrator, community, institution and society. Emphasis on general (primary) and targeted (secondary) prevention must remain paramount at all times in the development and implementation of child protection systems. Preventive measures offer the greatest return in the long term (para 46).

On the participation of children in the prevention of crime and the development of prevention strategies, the Committee (2009) noted that:

(...) the voices of children have increasingly become a powerful force in the prevention of child rights violations. (...) Children should be consulted in the formulation of legislation and policy related to these and other problem areas and involved in the drafting, development and implementation of related plans and programmes (para 118). ${ }^{13}$

The strategy also addresses the need to adopt special protection measures for groups of children which may be especially vulnerable. ${ }^{14}$ The Committee on the Rights of the Child has already drawn attention to the need for particular vigilance when it comes to various marginalized groups. It also provided a long list of children in potential vulnerable situations (Committee on the Rights of the Child, 201, para 72). ${ }^{15}$ The Model Strategies do not contain such a list, but it is easy to come up with a long list of potentially vulnerable groups of children. Such a list may include children working or living on the streets, children with disabilities, children suffering from mental illness, children of minority groups, unaccompanied children, migrant children, children who are refugees or asylum seekers, indigenous children, children living with HIV/AIDS, children with substance abuse problems, children of incarcerated parents $^{16}$, or children exposed to violence and harassment due to their sexual identity. 
Some of these vulnerable children are hardly visible because they are exploited in private spaces and highly vulnerable to violence. This is the case, for example, of children engaged in domestic work, most of them girls. According to the most recent figures published by the International Labour Organization (ILO), at least 52.6 million people are employed as domestic workers across the world, 15.5 million of whom are children (ILO, 2013, 1). A higher level of vigilance is required when it comes to protecting children from various marginalized groups such as children engaged in survival behaviours (e.g., prostitution) for which they are still more likely to be punished than assisted, or street children who are frequently treated by "police and communities... as a part of the larger crime problem, arbitrarily arresting, detaining and beating them, and forcing them to clean detention facilities" (Human Rights Watch, 2014, 5).

Unaccompanied asylum seeking children are also a most vulnerable group and those who have been trafficked present with additional needs, posing new challenges for law enforcement and child protection professionals (Rigby, 2011; UNICEF, 2014).

Civil society organizations, researchers, and other professionals have a role to play in identifying and studying the specific risk of victimization that different vulnerable groups of children face. Law enforcement agencies can also play an important role by using multi-agency intelligence to identify local risks of violence and direct enforcement and prevention activities.

Strategy II also calls for the development and implementation at every level of government of comprehensive plans for the prevention of violence against children in all of its forms. A comprehensive plan to eliminate violence against children must include general and context-specific prevention measures, be built on an understanding of factors that give rise to violence against children, and address the risks of violence to which children are exposed. The need for proactive, comprehensive, context-specific and sustainable prevention is emphasized as well as the need to understand and address the complex and multidimensional risk factors that increase the vulnerability of children, the different forms of neglect, exploitation and violence and how they may be interlinked, the harmful social norms and practices, the places where violations occur, the profiles of children at risk, and the profiles of offenders and exploiters. ${ }^{17}$ 
The Report of the independent expert for the United Nations study on violence against children refers to the need to challenge the societal acceptance of violence which explains that, in too many instances, both children and perpetrators may accept physical, sexual and psychological violence as inevitable and normal (United Nations, 2006, para 26; WHO, 2009).

\section{Promoting research and data Collection, analysis and dissemination}

Strategy III concerns the need to promote research and collect data on violence against children, including on violence against children in contact with the justice system. In most countries the current situation is that such data are rare and not very reliable. The strategy identifies specific types of data and research that should be encouraged as a practical basis for developing evidence-based policies and interventions and for monitoring the success of existing programmes.

For decision makers to be able to rely on a solid knowledge base upon which they can make decisions and design prevention activities, various forms of data must be collected, analysed and made broadly available. However, reliable information and data will not become available unless measures are taken to support, encourage and fund research and systematic data collection.

Sadly, despite calls for evidence-based planning, programming and decision-making, there is a lack of data on violence against children and very few quality evaluations and studies on the characteristics of successful prevention programmes (Proudlock, P., Mathews, A. and L. Jamieson, 2014; Dandurand, 2011).

Information about the risk of violence faced by children in contact with the criminal justice system is particularly critical and especially difficult to access. Accordingly, special attention must be given to collecting and analysing data on children's contacts with the police, on independent inspections of places of detention, access to complaint mechanisms by children and the outcomes of complaints and investigations. 


\section{Enhanced Criminal Justice Capacity}

The second group of strategies focuses on how to enhance the ability and capacity of the criminal justice system to respond to violence against children and protect child victims. It refers to its specific role in bringing perpetrators of violence against children to justice, protecting child victims of violence, and working closely together with other systems (education, welfare, child protection, health). In particular, this part of the instrument emphasizes the crucial importance of establishing detection and reporting mechanisms.

\section{Establishing effective detection and reporting mechanisms}

Strategy $I V$ involves the establishment of effective detection and reporting mechanisms. It refers to measures to ensure that criminal justice professionals are aware of risk factors and can recognize signs that a child is at risk, as well as measures to legally require professionals who routinely come into contact with children in the course of their work to notify appropriate authorities if they suspect that a child is, or is likely to become, a victim of violence. There is a pressing need to ensure that "safe child- and gender-sensitive approaches, procedures, and complaint, reporting and counselling mechanisms are established by law, are in conformity with the obligations of States under the relevant international human rights instruments, take into account relevant international standards and norms on crime prevention and criminal justice and are easily accessible to all children and their representative or a third party without fear of reprisal or discrimination" (Model Strategies, para 19d). These mechanisms are a core element of any successful child protection system. The performance of such mechanisms should be audited and their integrity tested regularly.

A joint report of the Special Representative of the Secretary-General on Violence against Children and the Special Rapporteur on the Sale of Children, Child Prostitution and Child Pornography explained that: "more often than not, children lack trust in available services, fearing they will not be believed and judged rather than listened to. They also frequently fear public exposure, stigmatization, harassment and reprisals if they make incidents of violence 
known. In most cases, children are unaware of the existence and role of counseling, reporting or complaint mechanisms" $(2012,21)$. Children often "simply do not know where to turn for help, especially when the perpetrator is a family member, caregiver, teacher or anyone else responsible for their protection and well-being." (SRSG - VAC, 2013, xiii)

In many jurisdictions legislation is in place to create obligations to report and receive reports. In British Columbia, for example, under the Child, Family and Community Service Act (CFCSA), child welfare workers receive reports from a person who has reason to believe that a child or youth has been, or is likely to be, physically, sexually, or emotionally abused and/or neglected. In these situations, child welfare workers must report allegations of child physical harm, sexual abuse and neglect to the police in accordance with existing protocols and collaborate on the investigation with the police. The Act also contains provisions for information sharing and sets the tone for what should be a very close cooperation between law enforcement and child protection agencies to prevent and reduce the incidence of violence against children. In practice, however, collaboration between the police and child protection agencies often remains sporadic if not problematic.

National legislation often provides for inter-agency reporting (between police and child protection organization) of incidents of violence against children, but the procedures and mechanisms in place to support this kind of reporting often remain deficient. The reporting mechanisms are not necessarily clear and their practical application is sometimes ambiguous. For example, in South Africa, under the Sexual Offences Act, professionals can report sexual offences to the police while under the Sexual Offences Act, everyone is obliged to report sexual offences to the police and everyone who fails to report is guilty of a criminal offence (Proudlock, Mathews, and Jamieson, 2014). Finally, in many if not most jurisdictions in the world, data on the complaints received and the responses that followed is neither routinely gathered nor publicly reported.

Another measure included in this strategy consists of adopting legislation, if necessary, and working with internet service providers, mobile phone companies, search engines, public internet facilities and others to facilitate the detection and the investigation of child pornography. 
The Internet is significantly misused as a tool for the dissemination of child pornography. ${ }^{18} \mathrm{~A}$ recent study conducted on behalf of the United Nations Office on Drugs and Crime highlighted how advances in information and communication technology facilitate criminal collaboration and communication across jurisdictions and borders with regard to the commission of acts of child abuse and exploitation (UNODC, 2014). Law enforcement agencies need the human resources, technical capacity and appropriate tools to thoroughly and effectively investigate such crimes.

\section{Offering effective protection to child victims of violence}

Strategy $V$ includes two groups of measures to ensure that the criminal justice system does as much as it can, in collaboration with child protection agencies, to protect child victims of violence against further violence and do so while using child-sensitive approaches. In particular, it refers to the need to ensure that national standards, procedures and protocols are developed and implemented in order to respond with sensitivity to child victims of violence who must be removed from a dangerous context and need temporary protection and care in a safe place pending a full determination of the best interests of the child. It also refers, among many other things, to the need to ensure that the police, courts and other competent authorities have the legal authority to issue and enforce protection measures such as restraining or barring orders in cases of violence against children, including removal of the perpetrator from the domicile and prohibiting further contact with the victim, as well as to impose penalties for breaches of those orders.

The measures ensure that the police, courts and other competent authorities have the legal authority to issue and enforce protection procedures such as restraining or barring orders in cases of violence against children, including removal of the perpetrator from the domicile and prohibiting further contact with the victim, as well as to impose penalties for breaches of those orders. It is equally important to ensure that, when the legal authority exists, these protection measures are diligently and consistently enforced and that any violation of a court ordered protection measure is dealt with seriously. To ensure that protection orders are enforced, it 
becomes important to establish a functional registration system (or registry) to keep track of these orders and make it possible for the police and other officials to quickly determine whether such an order is in force.

In British Columbia, the Representative for Children and Youth highlighted in several of her reports and submissions the need for supervised bail orders that can effectively enhance victim safety by careful monitoring of the behaviour of the accused. She noted that improvements to bail supervision practices are necessary to enhance family safety in this Province. In domestic violence situations, any reported bail violation should receive an immediate enforcement response. Yet, there remain issues in that province, as in many other parts of Canada, with the enforcement of conditions attached to court orders and the way violations of bail conditions are currently dealt with by the criminal justice system. There are reported cases of serious violence against children related to the failure of the justice system to respond when breaches of bail conditions occurred.

\section{Ensuring effective investigation and prosecution of incidents of violence against children}

Strategy VI is about the effective investigation and prosecution of incidents of violence against children. In countries such as Canada where there is a broad social awareness of the problem and a fairly high level of confidence in the police, a large number of cases are typically reported to the police each year. For example, there were 14,000 children who were victims of a police reported sexual offence in Canada in 2012 (Cotter \& Beaupré, 2014). In many cases, the victims delayed reporting the incident. In many instances, the identification of the perpetrator is a relatively simple matter, but the gathering of sufficient evidence to proceed with charges is often an arduous and time-consuming task.

Police must engage in proactive investigations whether the child or someone else has lodged an official complaint. Sufficient resources must be allocated to these investigations in order for the investigation and prosecution of violent crimes against children to be formally and practically identified as a system's priority. The Model Strategies invite countries to adopt and 
implement policies and programmes aimed at guiding all decisions concerning the investigation and prosecution of offences of violence against children and ensuring the fairness, integrity and effectiveness of such decisions.

The manner in which the investigation and the prosecution of offences of violence against children are conducted is also important. The safety of the child is a primary consideration. Training, operational policies, guidance tools and effective supervision are all needed to ensure that the investigation, including the collection of evidence, is conducted in a child-sensitive manner and respects their dignity and integrity.

\section{Enhancing cooperation among various sectors}

Strategy VII acknowledges the complementary roles of the criminal justice system, child protection, health, education, and social service sectors and, in some cases, informal justice systems in creating a protective environment and preventing and responding to incidents of violence against children. It urges States to ensure effective coordination and cooperation among these various systems and agencies and establish stronger operational links, particularly in emergency situations, between the agencies, while protecting the privacy of child victims of violence.

Westwood's study of officials in agencies working with children at a UK port of entry, for example, revealed a sense of isolation and fragmentation between the agencies involved and clear tensions between the safeguarding agendas and practices of the agencies involved. The interviews with social workers and police officers suggested that there was a lack of confidence and trust between agencies and in multi-agency approaches to safeguarding children entering the UK (2012). Other studies have revealed multiple obstacles to efficient inter-agency collaboration even when the safety of children is involved. Information exchange often seems to be particularly problematic.

For these reasons, some governments have taken very seriously the task of developing inter-agency cooperation protocols and providing specific guidance. For example, a "Working 
Together to Save Children" document was developed in the U.K. for practitioners and front line managers who have particular responsibilities for safeguarding and promoting the welfare of children and to senior and operational managers (U. K. Government, Department of Education, 2013). It includes both statutory and non-statutory guidance to practitioners. A second guidance document sets out how organisations and individuals should work together to safeguard and promote the welfare of children and young people from sexual exploitation (U. K. Government, Department of Education, 2014).

The most effective operational response to incidents of violence against children is usually through an integrated, multi-disciplinary specialized unit that can respond quickly and competently to the medical, psychological, social and legal needs of the child as well as his or her need for protection. The establishment of such specialized units should be considered.

In countries or regions where informal justice systems are frequently used, strong links between these systems and justice and child protection agencies are also necessary. In situations where a child's parents or caregivers are deprived of liberty, agencies from various sectors need to cooperate to support the child who, as a result, may be exposed to a greater risk of violence.

\section{Improving criminal proceedings in matters involving child victims of violence}

Criminal proceedings can be a very troubling and even traumatic experience for a child victim and this is often cited as a reason to avoid involving the criminal justice system in cases of violence against children. Over the last decade or so, a lot of effort has been made in Canada and in other countries to introduce child-sensitive procedures in cases involving child victims and witnesses of crime. The United Nations, for example, adopted in 2005 the Guidelines on Justice in Matters involving Child Victims and Witnesses of Crime ${ }^{19}$ and produced a Model Law on Justice in Matters Involving Child Victims and Witnesses of Crime (UNODC, 2009). In 2010, the Council of Europe adopted Guidelines on Child-Friendly Justice to help governments make sure that children are treated properly by and in the justice system (Kilkelly, 2010). Strategy VIII is largely inspired by these various instruments and proposes several measures that States should 
consider in developing legislation, procedures, policies and practices for children who are victims of crime or witnesses in criminal proceedings.

While bringing the necessary reforms to criminal procedure law and evidentiary law is complicated, child-sensitive procedures may include interview rooms designed for children, interdisciplinary services for child victims, collocated services for easy access, modified court environments that take child witnesses into consideration, recesses during a child's testimony, hearings scheduled at times of day appropriate to the age and maturity of the child, an appropriate notification system to ensure the child appears in court only when necessary and other appropriate measures to facilitate the child's testimony. There are different ways to implement such policies. In some countries, special "child justice units" or "child advocacy centres" are established in the courts. In other countries, a "child friendly bench" is established. On the other hand, the bringing of the necessary reforms to criminal procedure law and evidentiary law is sometimes more complicated.

\section{Ensuring that sentencing reflects the serious nature of violence against children}

Strategy $I X$ is meant to ensure that the serious nature of violence against children is reflected in sentencing practices and that, in doing so, courts have access to a full range of sentencing options. The seriousness of violent crimes against children must be reflected in sentencing policies and practices. Sentencing decisions must aim to denounce and deter violence against children. The legislator must ensure that such offences are, by law, punishable by appropriate penalties. It is also important to review the law and ensure that it takes into account specific factors which may aggravate a crime, including the age of the victim, the fact that the victim is severely handicapped mentally or intellectually, repeated violent acts, abuse of a position of trust or authority, and perpetration of violence against a child in a close relationship with the offender. Wherever possible, sentencing decisions should provide reparation for harm caused as a result of the violence. When informal justice systems are resorted to, violence against children needs to be appropriately denounced and deterred, perpetrators of violence against 
children must be held accountable for their actions, and redress, support and compensation for child victims must be provided.

The strategy, however, must acknowledge the fact that many of the perpetrators of violence against children are themselves children and that the principle of the best interest of the child applies whether the child is a victim or perpetrator of violence. Some of the criminal justice practices applied to child perpetrators of violence against children can have a very detrimental impact on their social and psychological development. This is the case, for example, of mandatory minimum sentences that are applied to children for certain types of offences (Dandurand, 2013). Another practice with detrimental effects on children is that of placing children on a sex offender registry: upon release from juvenile detention or prison, youth sex offenders are subject to registration laws that require them to disclose continually updated information including a current photograph, height, weight, age, current address, school attendance, and place of employment (Human Rights Watch, 2013).

\section{Strengthening capacity and training of criminal justice professionals}

Strategy $X$ refers to a host of measures required to build the capacity of the criminal justice system and criminal justice professionals to respond more effectively to violence against children. Very importantly, however, it also refers to the importance of training and the need to develop specialized expertise among these professionals and, when appropriate, to establish specialized teams and functions within the system. Competency-based training on appropriate, child sensitive and gender sensitive ways of dealing with child victims is especially important.

Specialized training is recommended (Penal Reform International, 2013). Criminal justice professionals must acquire some basic knowledge about the stages of child development, the process of cognitive development, the dynamics and nature of violence against children, the consequences of discrimination, the difference between regular peer groups and gangs, and the appropriate management of children who are under the influence of alcohol or drugs. The strategy also includes measures that can be taken by professional associations. 


\section{Preventing and Responding to Violence against Children Within the Justice System}

The third and final group of strategies relates to measures to prevent children from being victimized during their contact with the justice system (including the juvenile justice system where one exists). This is because of the heightened risk of violence faced by children alleged as, accused of, or recognised as having infringed the penal law. Considering that one important objective of the criminal justice system is the protection of children's rights, violence against children within that system thwarts its achievement and is counterproductive to any efforts of rehabilitation and reintegration of the child. It is also a sad thing to observe that many of the children in conflict with the law were themselves victims of abuse or neglect; being abused or neglected can nearly double a child's chance of having a youth justice record (Representative for Children and Youth \& Office of the Provincial Health Officer, 2009).

A recent statement of the Parliamentary Assembly of the Council of Europe is quite revealing about the lack of progress achieved in implementing juvenile justice reform:

(...) there is a considerable and continuing dissonance between the rhetoric of human rights discourse and the reality of juvenile justice interventions, in particular juvenile detention, for many children. Both the United Nations and the Council of Europe's monitoring bodies have identified a rather unsatisfactory situation with respect to the enforcement of human rights standards in the area of juvenile justice and detention. In this context, the over-representation of vulnerable children in detention has been considered alarming (Council of Europe, 2014).

The Model Strategies emphasize the need to prevent children from becoming involved in the criminal justice system and it introduces a number of measures for preventing the risk of violence against children at various stages of their contacts with that system. It recommends measures to limit the involvement of children in the justice system, prevent violence associated with law enforcement and prosecution activities, ensure that deprivation of liberty is only used as 
a measure of last resort, and prohibit violent, arbitrary or inhumane punishment of children. It contains a number of measures to detect, protect and assist children who are victims of violence as a result of their involvement with the justice system, including very important measures to prevent and respond to violence against children in places of detention. Finally, it identifies oversight and accountability measures that are crucial to the prevention of violence against children within the justice system.

A UNOHCHR/UNODC/SRSG-VAC joint report (2012) urged States:

to revise their laws, policies and procedures to ensure compliance with international standards and ensure that the process of juvenile justice reform is framed by a child- and gender-sensitive approach, promoting a juvenile justice system that is fair, effective, efficient, and established as a core dimension of the national child protection system ( $\mathrm{p}$. $15)$.

The principle of the best interest of the child (affirmed by Article 3(1) of the CRC), as it applies to crime prevention and the criminal justice process, is explained in General Comment No. 14 of the Committee on the Rights of the Child (2013). In a previous comment, the Committee had also explained that:

In all decisions taken within the context of the administration of juvenile justice, the best interests of the child should be a primary consideration. (...) The protection of the best interests of the child means, for instance, that the traditional objectives of criminal justice, such as repression/retribution, must give way to rehabilitation and restorative justice objectives in dealing with child offenders. This can be done in concert with attention to effective public safety (2007, para 10).

\section{Preventing children's involvement with the criminal justice system}

Strategy XI involves measures to reduce the number of children in contact with the justice system. There are several ways to limit the number of children in the criminal justice system. This may involve setting the lower minimum age of criminal responsibility at the age of at least 
12 years and to continue to increase that age. Doing so can, simply and effectively, reduce the number of children in the criminal justice system. However, care must be taken to ensure that those children who are below the age of criminal responsibility are not merely transferred into some other form of custodial care. It is therefore important to ensure that safe and effective noncustodial measures are available for the majority of children who are below that age.

The same objective can also be achieved by recognizing the importance of avoiding the unnecessary criminalization and penalization of children. In a number of countries, there is concern that too many children are brought into the criminal justice system through "status offences," leading to the placement of children in detention rather than providing them with the needed care and protection.

As we know, Article 40(3)(b) of the CRC states that: "Whenever appropriate and desirable, measures for dealing with such children without resorting to judicial proceedings, providing that human rights and legal safeguards are fully respected". In particular, diversion ${ }^{20}$ and restorative justice programmes are recommended (Moore, 2013; United Nations, Human Rights Council, 2014). A report of the International NGO Council on Violence against Children adds that diversion should not be limited to minor or first-time offences, but considered also wherever it would serve the best interest of the child (International NGO Council in Violence against Children, 2013). With respect to indigenous children, the Committee on the Rights of the Child encourages States to "take all appropriate measures to support indigenous peoples to design and implement traditional restorative justice systems as long as those programmes are in accordance with the rights set out in the Convention, notably with the best interests of the child" (Committee on the Rights of the Child, 2009a, para 75; see also, United Nations, Human Rights Council, 2014). The UN has adopted the Basic Principles on the Use of Restorative Justice Programmes in Criminal Matters ${ }^{21}$ which provides more specific guidance.

\section{Preventing violence associated with law enforcement and prosecution}

Strategy XII is about the prevention of violence and mistreatment associated with law enforcement and prosecution activities. The UN Study on Violence against Children (United 
Nations, 2006, p. 197) found that police and other security forces are often responsible for violence against children, and that arrest is one of the situations in which this occurs. The "Five Years On" follow up study found that children are at high risk of violence from their first point of contact with the law (NGO Advisory Council, 2011, p. 21). The strategy involves, among others things, ensuring that all arrests are conducted in conformity with the law, to limit the apprehension, arrest and detention of children to situations in which these measures are necessary as a last resort, and to promote and implement, where possible, alternatives to arrest and detention. As part of this strategy, it is most important to ensure that children are informed of their rights and have prompt access to legal aid during police interrogation and while in police detention, and that they may consult their legal representative freely and fully confidentially. Article 37 (d) of the CRC states that every child deprived of his or her liberty has a right to prompt access to legal and other appropriate assistance. The United Nations Principles and Guidelines on Access to Legal Aid in Criminal Justice Systems call upon States to ensure that effective legal aid is provided promptly at all stages of the criminal justice process. ${ }^{22}$

It is also crucial to establish accessible, child-appropriate and safe procedures for children to complain about incidents of violence during their arrest or interrogation or while in police custody. Access to these mechanisms can be particularly problematic when a child is being arrested or detained. Investigating and responding to these complaints also demands a degree of diligence and a level integrity that does not always exist.

\section{Limiting the use of detention}

A very important strategy, reflecting a principle enshrined in the CRC, is Strategy XIII which includes a number of measures to ensure that deprivation of liberty is used only as a measure of last resort and for the shortest appropriate period of time. Article 37(b) of the CRC stipulates that "the arrest, detention or imprisonment of a child shall be in conformity with the law and shall be used only as a measure of last resort and for the shortest appropriate period of time". Article 40(4) of the Convention stipulates that "a variety of dispositions, such as care, guidance and supervision orders; counselling; probation; foster care; education and vocational 
training programmes and other alternatives to institutional care shall be available to ensure that children are dealt with in a manner appropriate to their well-being and proportionate both to their circumstances and the offence." The Committee on the Rights of the Child mentioned the need to prevent violence in care and justice settings by "inter alia, developing and implementing community-based services in order to make use of institutionalization and detention only as a last resort and only if in the best interest of the child" (Committee on the Rights of the Child, 2011, para 47). The Bangkok Rules also recommend avoiding the institutionalization of children in conflict with the law to the maximum extent possible and adds that, when making such decisions, the "gender-based vulnerability of juvenile female offenders shall be taken into account in decision-making, 23 .

Alternatives to incarceration are particularly important in the case of Aboriginal children who, as a group, are often over-represented in detention facilities (Perreault, 2014). ${ }^{24}$ In British Columbia, Aboriginal children were found to be five times more likely to be incarcerated than youth in the general study population (Representative for Children and Youth \& Office of the Provincial Health Officer, 2009). A survey of youth in custody in that province in 2013 revealed that a little more than half of these youth were Aboriginal (McCreary Centre).

\section{Prohibiting certain treatments and punishments}

Strategy XIV is a simple one that reaffirms the prohibition against torture and other cruel, inhuman or degrading treatment or punishment, while Strategy $X V$ addresses the need to eliminate violence against children in places of detention.

\section{Preventing and responding to violence in places of detention}

Strategy XV addresses the prevention and response to violence in places of detention. Places of detention can be defined very broadly and during the preparation of the new instrument there were many references to the conditions of detention of irregular migrant or asylum-seeking children (Thomas \& Devaney, 2011) and, in other circumstances, the detention of children in 
military prisons (UNICEF, 2013). The strategy includes a large number of measures that can be taken to prevent violence against children in places of detention, including measures to prevent over-crowding, to separate children from adults, to ensure that child-sensitive policies, procedures and practices are implemented in all detention facilities, and to monitor compliance with them.

It is also necessary to prohibit and effectively prevent the use of corporal punishment as a disciplinary measure, to adopt clear and transparent disciplinary policies and procedures that encourage the use of positive and educational forms of discipline and to establish in law the duty of managers and personnel of detention facilities to record, review and monitor every instance in which disciplinary measures or punishment are used.

Very importantly, the strategy refers to strict measures to be taken to ensure that all alleged incidents of violence, including sexual abuse of children in a place of detention, are immediately reported and independently, promptly, and effectively investigated by appropriate authorities and, when well founded, effectively prosecuted.

Finally, in view of the crucial importance of independent monitoring and inspection mechanisms, measures are recommended to ensure effective monitoring of, regular access to and inspection of places of detention by independent bodies, human rights institutions, ombudspersons or members of the judiciary, who are empowered to conduct unannounced visits, conduct interviews with children and staff in private and investigate allegations of violence.

\section{Detecting, assisting and protecting children victims of violence in the justice system}

Strategy XVI addresses the need to detect, assist and protect children victimized as a result of their involvement with the justice system as alleged or sentenced offenders. It refers, among other things, to the crucial importance of establishing complaint mechanisms for child victims of violence within the justice system that are safe, confidential, effective and easily accessible. The International NGO Council on Violence against Children noted that " $(\mathrm{t}) \mathrm{he}$ 
absence of meaningful complaint mechanism leaves children involved in the juvenile justice system with little recourse when violence is perpetrated against them. Children all too often have no avenue to draw attention to police or institutional violence other than through the police or institutions themselves" (2013, p. 24).

Once complaint mechanisms are established it is also very important to protect children who report abuse, specifically taking into account the risks of retaliation. This can be done by adopting and enforcing policies that ensure that those allegedly implicated in violence against or ill-treatment of children are removed from any position of control or power, whether direct or indirect, over complainants, witnesses and their families, and those conducting the investigation. Other practical and procedural measures must be in place to protect children who provide information or act as witnesses in proceedings related to a case involving violence within the justice system.

In accordance with the Declaration of Basic Principles of Justice for Victims of Crime and Abuse of Power, States have a duty to ensure that child victims are provided with appropriate access to justice and fair treatment, restitution, compensation and social assistance. ${ }^{25}$

\section{Accountability and oversight mechanisms}

The last strategy in this group (Strategy XVII) is concerned with strengthening accountability and oversight mechanisms within the criminal justice system. It includes a number of measures to promote transparency and combat impunity and the tolerance of violence against children within the justice system, including awareness-raising programmes, education and effective prosecution of violent offences committed against children within the justice system. There is also a need to establish all key elements of an effective accountability system, ensure the independent, prompt and effective investigation and prosecution of offences involving violence against children within the justice system, and ensure that all public officials who are found to be responsible for violence against children are held accountable through workplace disciplinary measures, termination of employment and criminal justice investigations, where appropriate. 


\section{Conclusion}

The article could only summarize some of the key practical measures identified in the new instrument. This will hopefully be enough to encourage practitioners and policy makers to study the instrument itself and identify gaps in their own systems and procedures. Because it is quite comprehensive, the instrument can actually be used to assess the situation in a present country or to evaluate progress in improving the criminal justice response to violence against children. In fact, a checklist, based on the Model Strategies, has been developed and is now available from the United Nations Office on Drugs and Crime (UNODC, 2014a). At the same time, the Model Strategies can be expected to encourage practitioners and researchers to explore and test different means of implementing the proposed strategies, evaluate their impact, and share information and best practices.

States currently face many difficulties in improving child protection practices and systems, particularly in a time of fiscal constraints (Moore, 2013). In Canada, as elsewhere, the criminal justice system is capable of playing a much greater and more effective role in preventing violence against children. It needs to be fully mobilized. There is also a dire need for greater clarity and more rigorous evidence about the best ways to prevent and respond to violence against children through the justice system as well as every other available means. The Model Strategies can perhaps encourage progress toward that goal.

\section{Notes}

\section{A/C.3/67/L.34, operative paragraph 30.}

2 Note that the UN has already adopted a comparable set of Model Strategies and Practical Measures on the Elimination of Violence against Women in the Field of Crime Prevention and Criminal Justice, General Assembly Resolution 52/86; and, the Updated Model Strategies and Practical Measures on the Elimination of Violence against Women in the Field of Crime Prevention and Criminal Justice, General Assembly resolution $65 / 228$, annex.

3 Optional Protocol to the Convention on the Rights of the Child on the sale of children, child prostitution and child pornography, General Assembly resolution 54/263, annex II. 

supplementing the United Nations Convention against Transnational Organized Crime, General Assembly resolution 55/25, Annex II.

5 Committee on the Rights of the Child (2011), para 24. The United Nations Guidelines for the Prevention of Juvenile Delinquency state that "No child or young person should be subjected to harsh or degrading correction or punishment measures at home, in schools or in any other institutions", General Assembly resolution 45/112, annex, para 54.

6 See also to the Committee on the Rights of the Child (2011), para 29. See also United Nations (2006), paragraphs 44 and 100 .

7 The Global Initiative to End All Corporal Punishment of Children reports numerous national and comparative studies on the prevalence of corporal punishment and attitudes towards it in the following countries which have prohibited all corporal punishment. http://www.endcorporalpunishment.org/pages/frame.html.

8 General Assembly resolution 54/263.

9 General Assembly resolution 55/25, Annex II.

10 Article18 of the Council of Europe 2007 Convention on the Protection of Children against Sexual Exploitation and Sexual Abuse requires the criminalization of the following conducts: "(a) engaging in sexual activities with a child who, according to the relevant provisions of national law, has not reached the legal age for sexual activities; (b) engaging in sexual activities with a child where: use is made of coercion, force or threats; or abuse is made of a recognised position of trust, authority or influence over the child, including within the family; or abuse is made of a particularly vulnerable situation of the child, notably because of a mental or physical disability or a situation of dependence.” CETS 201 - Protection of Children against Sexual Exploitation and Sexual Abuse, 25.X.2007.

11 Convention Concerning the Prohibition and Immediate Action for the Elimination of the Worst forms of Child Labour, 1999 (No. 182), International Labour Organization.

12 The reference to playing "a leadership role" is consistent with the United Nations Guidelines for the Prevention of Crime, Economic and Social Council resolution 2002/13, annex, para 7.

13 On the participation of child victims, see also the 2012 Report of the Special Rapporteur on the sale of children, child prostitution and child pornography.

14 A similar measure was included in the Guidelines for Action on Children in the Criminal Justice System, Economic and Social Council resolution 1997/30, annex. Guideline 17 states that: “Appropriate action should ensure to alleviate the problem of children in need of special protection measures, such as children working or 
living on the streets or children permanently deprived of a family environment, children with disabilities, children of minorities, immigrants and indigenous peoples and other vulnerable groups of children."

15 See also: Committee on the Rights of the Child (2003), para 38; and (2006a), para. 42.

16 See: Manning, R. (2011); McCormick, A. V., Millar, H. A. and G. Paddock (2014).

17 See also: Committee on the rights of the Child (2011, para 72); UNICEF, UNHCR, Save the Children and World Vision (2013); WHO (2006).

18 See: Report of the Special Rapporteur on the sale of children, child prostitution and child pornography (United Nations, 2013)

19 Guidelines on Justice in Matters involving Child Victims and Witnesses of Crime, Economic and Social Council resolution 2005/20, annex.

20 See: United Nations Standard Minimum Rules for the Administration of Juvenile Justice, General Assembly resolution 40/33, annex, rules 11.1, 11.2, 11.3.

21 See, in that regard, the Basic Principles on the Use of Restorative Justice Programmes in Criminal Matters, Economic and Social Council resolution 2002/12, annex. Also: UNODC (2006). See also: SRSG on Violence against Children (2013).

22 United Nations Principles and Guidelines on Access to Legal Aid in Criminal Justice Systems, Economic and Social Council resolution 2005/20, annex, Principle 7.

23 United Nations Rules for the Treatment of Women Prisoners and Non-custodial Measures for Women Offenders (Bangkok Rules), General Assembly resolution 65/229, annex, Rule 65.

24 See: Committee on the Rights of the Child (2009a, para 74).

25 Declaration of Basic Principles of Justice for Victims of Crime and Abuse of Power, General Assembly resolution 40/34.

\section{References}

Bokhari, S. (2009). Stolen Futures: Trafficking for Forced Child Marriages in the U. K. London: EKPAT UK/ WISE.

Bokhary, F., \& Kelly, E. (2010). Child Rights, Culture and Exploitation: UK Experiences of Child Trafficking. In G. Craig (ed.), Child Slavery Now (pp.145-159). London: The Policy Press. 
Committee on the Rights of the Child. (2003). General Comment No. 3 - HIV/AIDS and the rights of the child.

Committee on the Rights of the Child. (2006). General Comment No. 8. - The right of the child to protection from corporal punishment and other cruel or degrading forms of punishment.

Committee on the Rights of the Child. (2006a). General Comment No. 9 - The rights of children with disabilities.

Committee on the Rights of the Child (2007). General Comment No. 10 - Children's Rights in Juvenile Justice.

Committee on the Rights of the Child (2009). General Comment No. 12 - The rights of the child to be heard.

Committee on the Rights of the Child (2009a). General Comment No. 11 - Indigenous children and their rights under the convention.

Committee on the Rights of the Child (2011). General Comment No. 13 - The right of the child to freedom from all forms of violence.

Committee on the Rights of the Child (2013). General Comment No. 14 - The right of the child to have his or her best interests taken as a primary consideration.

Cotter, A., \& P. Beaupré. (2014). Police-reported sexual offences against children and youth in Canada, 2012. Juristat, Ottawa: Canadian Centre for Justice Statistics.

Council of Europe - Parliamentary Assembly. (2014). Child Friendly Justice: From rhetoric to reality, Resolution 2010 (2014). Text adopted by the Assembly on 27 June 2014 (27th Sitting). 
Dandurand, Y. (2011). Criteria for the Design and Evaluation of Juvenile Justice Reform Programmes. UNODC and Interagency Panel on Juvenile Justice. New York: United Nations.

Dandurand, Y. (2012). Exemptions from Mandatory Minimum Penalties. A report prepared for the Uniform Law Conference of Canada, Working Group on Exemptions from Mandatory Minimum Penalties, Ottawa, Canada.

Gangoli, G., Razak, A., \& McCarry, M. (2006). Forced Marriage and Domestic Violence among South Asian Communities in North East England. Bristol: University of Bristol and North Rock Foundation.

Human Rights Watch. (2013). Raised on the Registry - The irreparable harm of placing children on sex offender registries in the US. Washington (D.C.): HRW, May 2013.

Human Rights Watch. (2014). "Where Do You Want Us to Go?" - Abuses against Street Children in Uganda, Kampala: URW.

International Labour Organization. (2013). Ending Child Labour in Domestic Work and Protecting Young Workers for Abusive Working Conditions. Geneva: ILO.

International NGO Council in Violence against Children. (2013). Creating a Non-Violent Juvenile Justice System, October 2013.

Kilbanem, T. (2013). Addressing Violence and Abuse - Global Data Collection on Child Discipline. Bangkok: UNICEF EAPRO.

Kilkelly, U. (2010). Guidelines on Child-friendly Justice: A summary. Document prepared by the Directorate General of Human Rights and Legal Affairs, Council of Europe, Strasbourg, 15 December. 
League of Arab States. (2010). The Comparative Arab report on implementing the recommendations of the UN Secretary-General's Study on Violence against Children. Cairo: League of Arab States.

Manning, R. (2011) Punishing the Innocent: Children of Incarcerated and Detained Parents, Criminal Justice Ethics, 30 (3), 267-287.

McCormick, A. V., Millar, H. A. and G. Paddock. (2014). In the Best Interests of the Child: Strategies for Recognizing and Supporting Canada's At-Risk Population of Children with Incarcerated Parents. Abbotsford (B.C.): Centre for Safe Schools and Communities, University of the Fraser Valley.

McCreary Centre. (2013). Time Out III - A profile of BC youth in custody. Vancouver: McCreary Centre Society, August.

Moore, M. (2013). Protect Society and Realise Youth Potential. Improving Youth Justice Practice in a Time of Economic Crisis. Brussels: International Juvenile Justice Observatory.

NGO Advisory Council. (2011). Five Years On: A global update on violence against children. A report from the NGO Advisory Council for follow-up to the UN Secretary-General's Study on Violence against Children, October 2011.

OHCHR/UNODC/SRSG-VAC. (2012). Joint Report of the Office of the High Commissioner for Human Rights, the United Nations Office on Drugs and Crime and the Special Representative of the Secretary General on Violence against Children on prevention of and response to violence against children within the juvenile justice system, June 2012, $\mathrm{A} / \mathrm{HRC} / 21 / 25$.

Penal Reform International. (2013). Protecting Children's Rights in Criminal Justice Systems: A training manual and reference point for professionals and policymakers. London: PRI. 
Perreault, S. (2013). Admissions to Youth Correctional services in Canada, 2011-2012. Ottawa: Statistics Canada.

Phillips, R. (2012). Interventions Against Forced Marriage: Contesting Hegemonic Narrative and Minority Practices in Europe. Gender, Place and Culture, 19 (1), 21-41.

Proudlock, P., Mathews, A. and L. Jamieson. (2014). Children's rights to be protected from violence: A review of South Africa's laws and policies. In P. Proudlock (Ed.), South Africa's Progress in Realising Children's Rights - A Law Review (pp. 166-212). Cape Town: University of Cape Town, Children's Institute, Save the Children.

Representative for Children and Youth \& Office of the Provincial Health Officer. (2009). Kids, Crime and Care - Health and Well-Being of Children in Care: Youth Justice Experiences and Outcomes. Victoria, February 23.

Rigby, P. (2011) Separated and Trafficked Children: The Challenges for Child Protection Professionals, Child Abuse Review, 20, 324-340.

Special Representative of the Secretary General on Violence against Children. (2013). Promoting Restorative Justice for Children. New York: United Nations.

Special Representative of the Secretary General on Violence against Children \& Plan. (2012). Protecting Children from Harmful Practices in Plural Legal Systems with a Special Emphasis on Africa. New York: Office of the Special Representative of the Secretary on Violence against Children.

Special Representative of the Secretary-General on Violence against Children \& Special Rapporteur on the Sale of Children, Child Prostitution and Child Pornography. (2012). Safe and Child-sensitive Counselling, Complaint and Reporting Mechanisms to Address Violence against Children. Geneva: UNOHCHR. 
Special Representative of the Secretary General on Violence against Children. (2013). Toward a World Free from Violence - Global Survey on Violence against Children. New York: Office of the Special Representative of the Secretary-General on Violence against Children.

Thomas, N., \& J. Devaney. (2011). Safeguarding Refugee and Asylum-seeking Children. Child Abuse Review, 20, 307-310.

U.K. Government, Department of Education. (2013). Working Together to Safeguard Children: A guide to inter-agency working to safeguard and promote the welfare of children. London: H.M. Government.

U.K. Government, Department of Education. (2014). Safeguarding Children and Young People from Sexual Exploitation. London: H.M. Government.

UNICEF. (2013). Children in Israeli Military Detention - Observations and Recommendation. Jerusalem, February.

UNICEF. (2014). Hidden in Plain Sight - A statistical analysis of violence against children. New York: UNICEF.

UNICEF, UNHCR, Save the Children \& World Vision. (2013). A Better Way to Protect ALL Children: The Theory and Practice of Child Protection Systems, Conference Report, New York: UNICEF.

United Nations. (2006). Report of the independent expert for the United Nations study on violence against children. A/61/299, 29 August 2006.

United Nations. (2013). Report of the Special Rapporteur on the sale of children, child prostitution and child pornography, Najat Maalla M'jid, A/HRC/25/48, 23 December 2013. 
United Nations, Human Rights Council. (2014). Annual Report of the Special Representative of the Secretary-General on Violence against Children, A/HRC/25/47, 3 January 2014.

United Nations Population Fund. (2012). Marrying Too Young - End Child Marriage. New York: United Nations.

UNODC. (2006). Handbook on Restorative Justice Programmes. New York: United Nations.

UNODC. (2009). Justice in Matters Involving Child Victims and Witnesses of Crime, Model Law and Commentary. New York: United Nations.

UNODC. (2014). Study facilitating the identification, description and evaluation of the effects of new information technologies on the abuse and exploitation of children, E/CN.15/2014/CRP.

UNODC. (2014a). Planning the Implementation of the United Nations Model Strategies and Practical Measures on the Elimination of Violence against Children in the Field of Crime Prevention and Criminal Justice - A Checklist. Vienna: UNODC.

Westwood, J. L. (2012). Constructing Risk and Avoiding Need: Findings from Interviews with Social Workers and Police Officers Involved in Safeguarding Work with Migrant Children. Child Abuse Review, 21, 349-361.

WHO. (2006). Preventing Child Maltreatment: A Guide to Taking Action and Generating Evidence. Geneva: World Health Organization.

WHO. (2009). Violence Prevention - The Evidence. Changing cultural and social norms that support violence. Geneva: World Health Organization. 